\title{
Thermodynamic and Kinetic Stability of Anthocyanidin: DFT
}

\section{and TD-DFT Calculation}

\author{
Asmaa B. El-Meligy, ${ }^{1}{ }^{1}$ and Ahmed H. Mangood. ${ }^{1}$ \\ ${ }^{1}$ Chemistry Department, Faculty of Science, Menoufia University, Shebin El-Kom, Egypt \\ asmaaphys@yahoo.com
}

\section{ABSTRACT}

In this study, the thermodynamic and kinetic stability of cyanidin were investigated using density functional theory (DFT) and time-dependent DFT (TD-DFT) methods. The stability of cyanidin as a simple anthocyanidin has been described and the effect of keto-enol tautomerization on the color instability of this pigment relative to other counterparts with 3-O-substitution has been analyzed. The results reveal that the keto form at 3-position is thermodynamically preferable and the keto structure of chalcone (a secondary product of cyanidin hydration) is thermodynamically and kinetically preferable compared to the keto-structure of cyanidin flavylium cation. Therefore, the 3-hydroxyl group is responsible for cyanidin color instability and plays an important role in decomposition of anthocyanidin.

Keywords: Cyanidin, Stability, TD (TD-DFT), keto-enol tatuomerization, anthocyanidin.

\section{Corresponding Author: El-Meligy A. B.}

\section{INTRODUCTION}

Anthocyanin compounds are considerable to be highly useful plant pigments that can be used in many applications. It can be used as food colorants [1-3], pigments in dye sensitized solar cell $[4,5]$ antioxidants [6-9], anti-tutomer, anti-inflammatory, anticarcinogenic [2,10-14] and also as indicators [15]. They are responsible for red, pink, and blue colors of flowers, vegetables and fruits [1620].Anthocyanin structures differ in the number of hydroxy and methoxy groups of the 2phenylbenzopyrylium moiety (flavylium cation) [21]. Naturally occurring anthocyanins are always glycosylated at the C-3 position [22]. Anthocyanidins are the sugar-free anthocyanin chromophore that can be easily prepared by the acidic hydrolysis of glycoside residue. The main drawback reported for the anthocyanidins is their color instability; they are highly reactive and degrade under normal conditions and their color change to colorless compounds.

It was known that anthocyanidins exist in equilibrium (Scheme 1) in an aqueous solution depending on the $\mathrm{pH}$. The red flavylium cation $\left(\mathbf{A H}^{+}\right)$of the strong acidic medium is transformed to purple quinoidal base (A) at neutral solutions and further into blue quinoidal base anion $\left(\mathbf{A}^{-}\right)$at the 
basic medium (by proton transfer). Hydration of $\mathbf{A H}^{+}$to colorless hemiketal (pseudobase, $\mathbf{B}$ ) in weakly acidic medium takes place followed by formation of chalcone $(\mathbf{C})$ via ring opening of $\mathbf{B}$ [23-25]. It is supposed to inhibit the hydration and proton transfer reactions to preserve the red color of flavylium cation. The color stability of natural anthocyanins $[1,26-28]$ have been ascribed to chemical structure and position of the substituents of anthocyanin $[29,30]$ especially sugar $[29,31]$ as well as other factors such as binding with metal ions [32] or other pigments [25]. Even though, variety of reports about anthocyanin stability have been intensively investigated and most of them are based on nature of anthocyanin structure [33,29,34,35,27,28,36,37], The high stability of 3-O-glucoside moieties than 3hydroxyl anthocyanin haven't yet been understood [29,31]. Quantum chemical calculations provide a reliable rapid screening of the possibility of another suggested mechanism that can interpret color change in anthocyanidins under different conditions (Scheme 2) with saving time and resources. Therefore, we carried out such computational work to investigate possible conversion of cyanidin to keto structure using density functional theory.<smiles>Oc1cc(O)c2cc(O)c(-c3ccc(Cl)c(O)c3)[o+]c2c1</smiles>

flavylium cation $\left(\mathrm{AH}^{+}\right)$

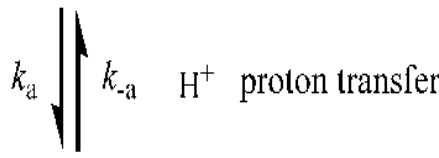<smiles>O=c1cc2oc(-c3ccc(O)c(O)c3)c(O)cc-2c(O)c1</smiles>
quinonoidal base

(A)

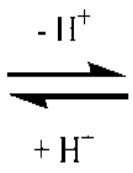

quinonoidal base anaion

$\left(\mathrm{A}^{-}\right)$<smiles>[Y]C(=C)[C@H](C)C=C</smiles>

$\mathrm{H}^{+}$ tautomerization cis-chalcone
(B)<smiles>O=c1cc2oc(-c3ccc(O)c([O-])c3)c(O)cc-2c(O)c1</smiles><smiles>O=C(/C=C(\O)c1ccc(O)c(O)c1)c1ccc(O)cc1O</smiles>

trans-chalcone

(Ct)

Scheme 1: Transformation equilibria of cyanidin in aqueous solution. 


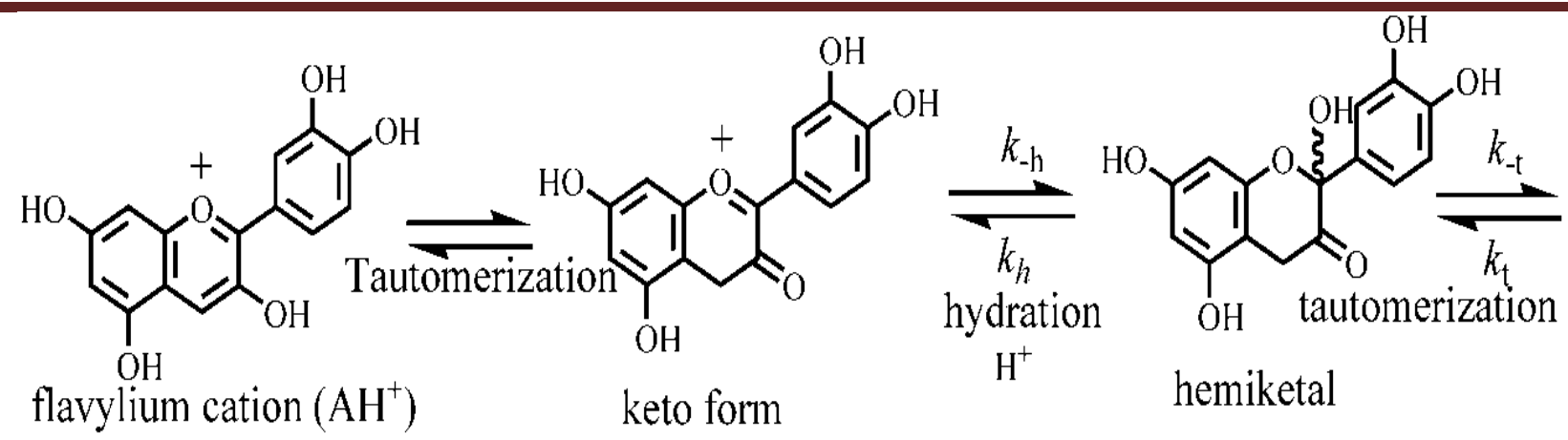

enol form

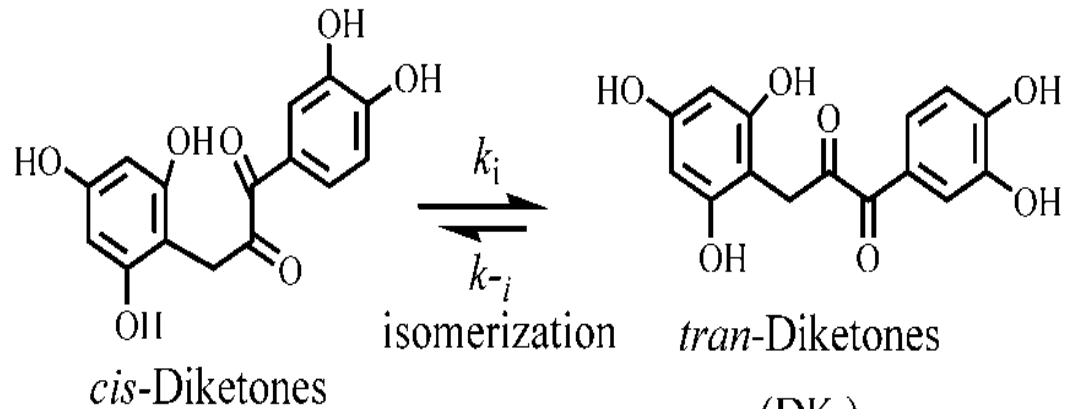

$\left(\mathrm{DK}_{\mathrm{C}}\right)$

$\left(\mathrm{DK}_{1}\right)$

Scheme 2: Keto-enol tautomerization of cyanidin in aqueous solution

\section{COMPUTATIONAL DETAILS.}

The most stable cyanidin conformer has been optimized using hybrid density functional theory with the dispersion corrected [38,39]. The B3P86-D2 method accurately described anthocyanin conformers [38,40], their thermodynamic [41] and absorption properties. Therefore, geometry optimizations of the keto and enol forms were carried out with the B3P86-D2 functional along with the cc-pVDZ basis set. The electronic properties were calculated using time-dependent DFT (TD-DFT) at the same level of optimization. The effect of presence of solvent such as water was examined using solvation model based on density (SMD) [42]. All calculations were carried out using Gaussian 09 program [43].

\section{RESULTS AND DISCUSSION}

\section{Conformer of cyanidin}

Cyanidin has a numbers of hydroxyl groups with different orientation. It is anticipated, from the small differences in the calculated energy (Figure 1), that most of conformers are possible in solution. Figure 1 shows relative zero-point corrected energies and free energies of all possible conformers at B3P86-D2/cc-pvdz in water. Figure 2 displays the structures of the most stable conformers of cyanidin with a relative energy difference of about $2 \mathrm{kcal} / \mathrm{mol}$. Energy difference between the two most stable $\mathbf{A}$ and I structures is modest; $\mathbf{A}$ is more stable than $\mathbf{I}$ by $0.14 \mathrm{kcal} / \mathrm{mol}$. The stability of them might be ascribed to strong hydrogen bond formed by such pattern of the hydroxyl group orientation. From hereinafter we will consider conformer $\mathbf{A}$ of cyanidin for further discussion $(\mathbf{C y})$. 


\section{Keto-enol tautomerization}

The thermodynamic and kinetic for keto-equilibrium structures of cyanidin starting from flavylium cation to the quinonoidal base passing through hemiketal and chalcone structures were investigated and compared with the keto-structures. Figure 3 depicts the potential energy diagram for the equilibrium from keto and enol flavylium cation. Figure 4 clearly shows the optimized equilibrium structures of cyanidin. Throughout this study three possible quinonoidal bases $\left(\mathbf{A}_{\mathbf{4}}, \mathbf{A}_{\mathbf{5}}, \mathbf{A}_{\mathbf{7}}\right)$ have been considered. It will be easier to theoretically determine the equilibrium constant for $\mathrm{H}$ transfer reaction (acid-base equilibrium between $\mathbf{A H}^{+}$and the possible $\mathbf{A}$ ). The equilibrium constant can be estimated from the relation $\Delta G^{0}=-R T \ln K_{a}$ where $\Delta G^{0}$ is the standard Gibbs energy, $\mathrm{R}$ gas constant, $\mathrm{T}$ the absolute temperature in kelvin and $\mathrm{K}_{\mathrm{a}}$ is the equilibrium constant. As reported previously [44], the proton transfer products (A) are kinetic products and disappear rapidly due to their instability, the higher free energy (22.8-24.9 kcal/mole) was found to $\mathbf{A}_{\mathbf{4}}, \mathbf{A}_{\mathbf{5}}, \mathbf{A}_{\mathbf{7}}$ formation. Other process like hydration, tautomerization and isomerization have their corresponding equilibrium constants $K_{h}, K_{t}$ and $K_{i}$. The overall equilibrium is equivalent to combination of them. Hydration reaction and isomerization to keto form are thermodynamically in competition but the keto form is more thermodynamically favored. For the kinetic process taking place in the network of $\mathbf{A H}^{+}$chemical reactions, the barriers for the keto formation from $\mathbf{A} \mathbf{H}^{+}$and from cis-chalcone (diketones) have been compared. The barrier height is lower in case of chalcone isomerization to 3-keto structure (49.1 $\mathrm{kcal} / \mathrm{mole})$ than flavylium cation isomerization to the 3 -keto form $(69.4 \mathrm{kcal} / \mathrm{mole})$.

Both the hemiketal (B) from the keto and the enol forms of $\mathbf{A} \mathbf{H}^{+}$are involved in a tautomeric process that leads to the ring opening with formation of a cis-chalcone form. This reaction with keto form is again thermodynamically favored than the one occurs from enol-form. The diketones (DK) resulted from hemiketal ring opening is stable by $8.6 \mathrm{kcal} / \mathrm{mole}$ than cis-chalcone resulted from enol form. Even though the lower energy of tautomerization $(1.7 \mathrm{kcal} / \mathrm{mole})$ for keto form, the enol form needs $2.5 \mathrm{kcal} / \mathrm{mole}$ for tautomerization. Finally, depending on the flavylium substitution pattern the cis-chalcone thermally isomerizes and gives the trans-chalcone.

a)

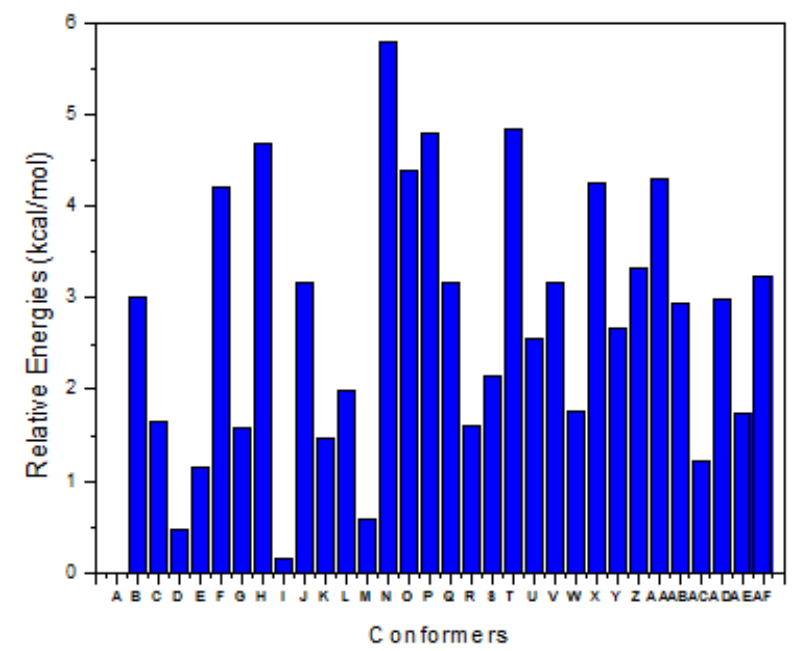

b)

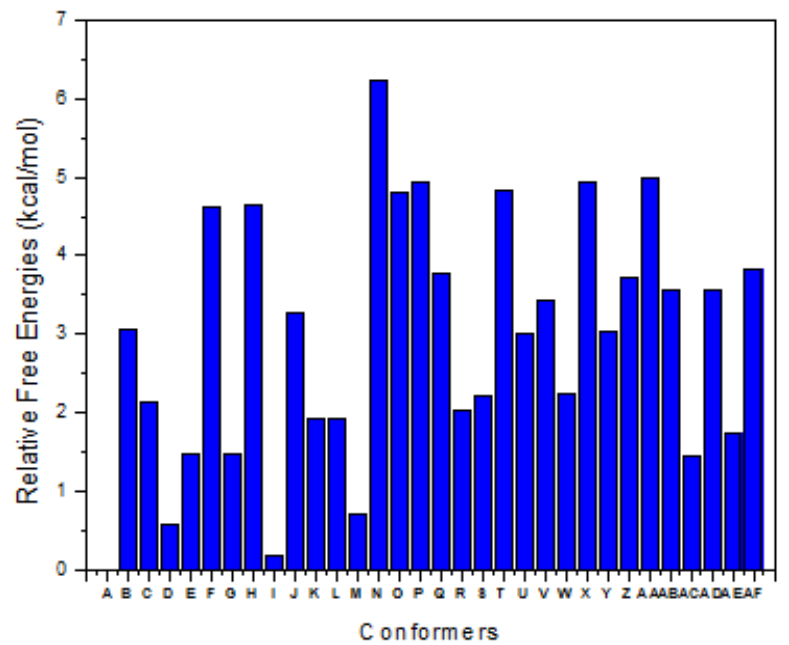

Figure 1: Relative stabilities of cyanidin conformers relative to $\mathbf{A}$ at B3P86-D2/cc-pVDZ in water. a) zero-point corrected energies and b) free energies. 


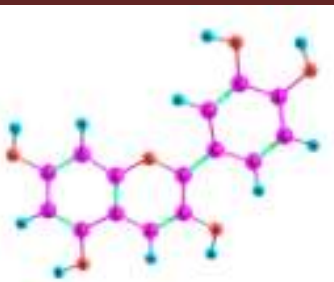

A

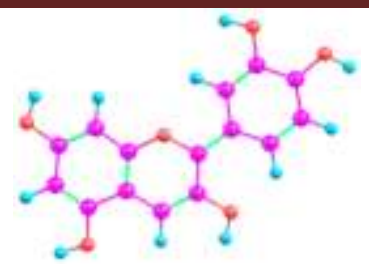

C

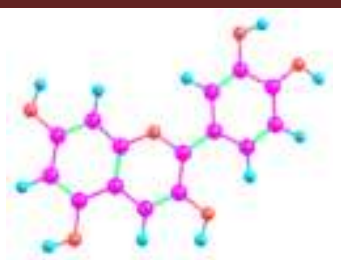

D

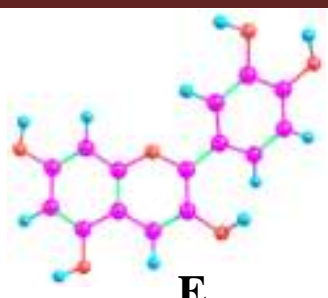

1.15

$\mathrm{E}+\mathrm{ZPE}$

0.00

1.66

0.47

2.12

$\mathrm{G}$

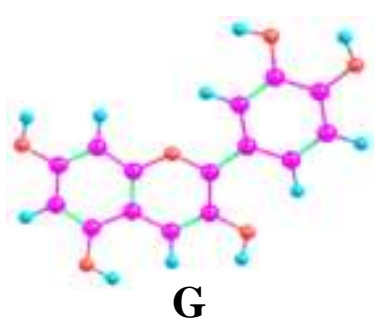

$\mathrm{E}+\mathrm{ZPE}$

$\mathrm{G}$

1.58

1.47

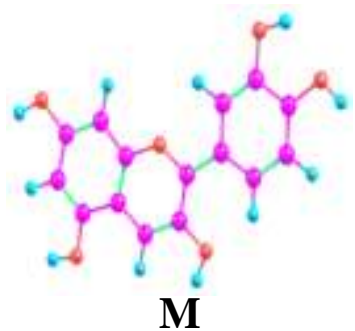

0.59

E+ZPE

0.71

$\mathrm{G}$

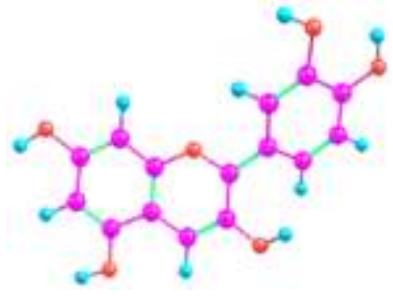

AC

$\mathrm{E}+\mathrm{ZPE}$

G

1.23

1.45

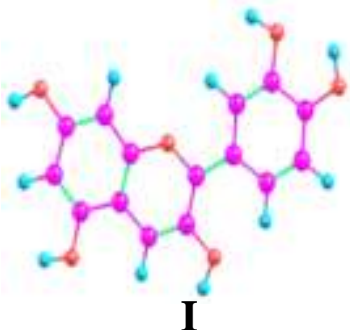

0.14

0.19

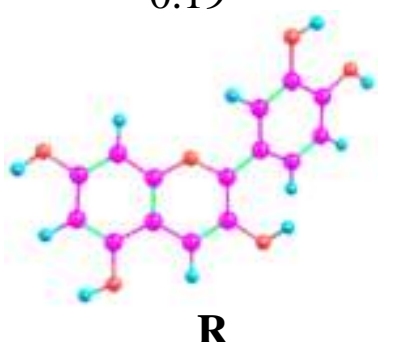

R

1.61

2.03

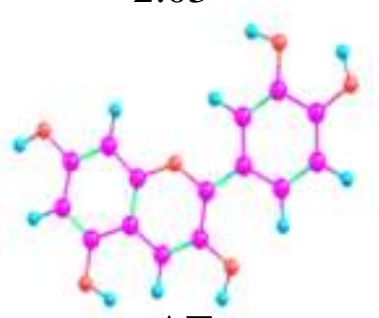

AE

0.59

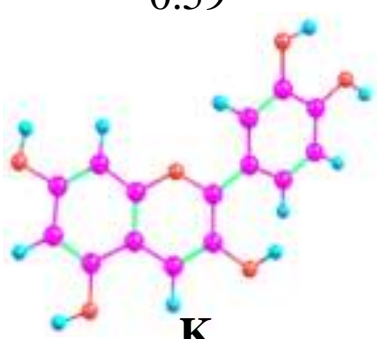

K

1.47

1.93

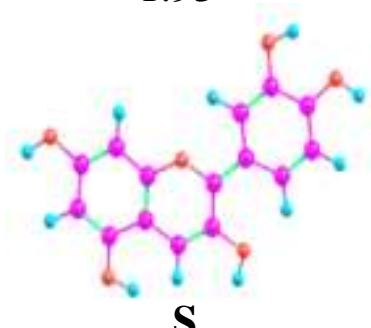

2.15

2.21

1.47

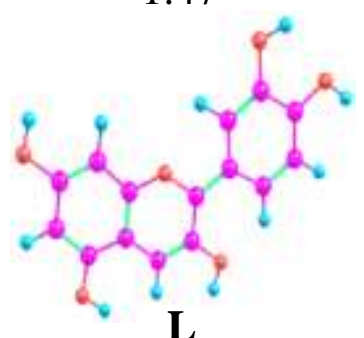

1.98

1.93

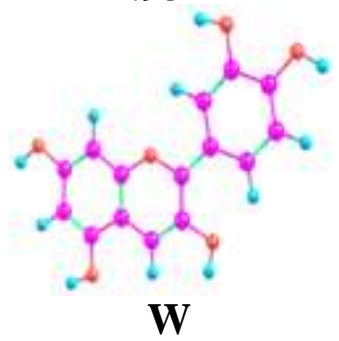

1.77

2.25

Figure 2: Optimized structures of most stable cyanidin conformers at B3P86-D2/cc-pVDZ in water through SMD.

The $p K_{a}$ calculation

For determining the $p K_{a}$ the solvation free energies use thermodynamic cycle has been utilized. Table 1 collects the calculated $K_{a} K_{h}, K_{t}$ and $K_{i}$ and avialable experimentsl data. The calculated value of $p K_{a}$ are in the range of 9.50 and 11.0, while the experimental date is 4.8 indicating a double overestimated of the calculated $p K_{a}$ of cyanidin. 


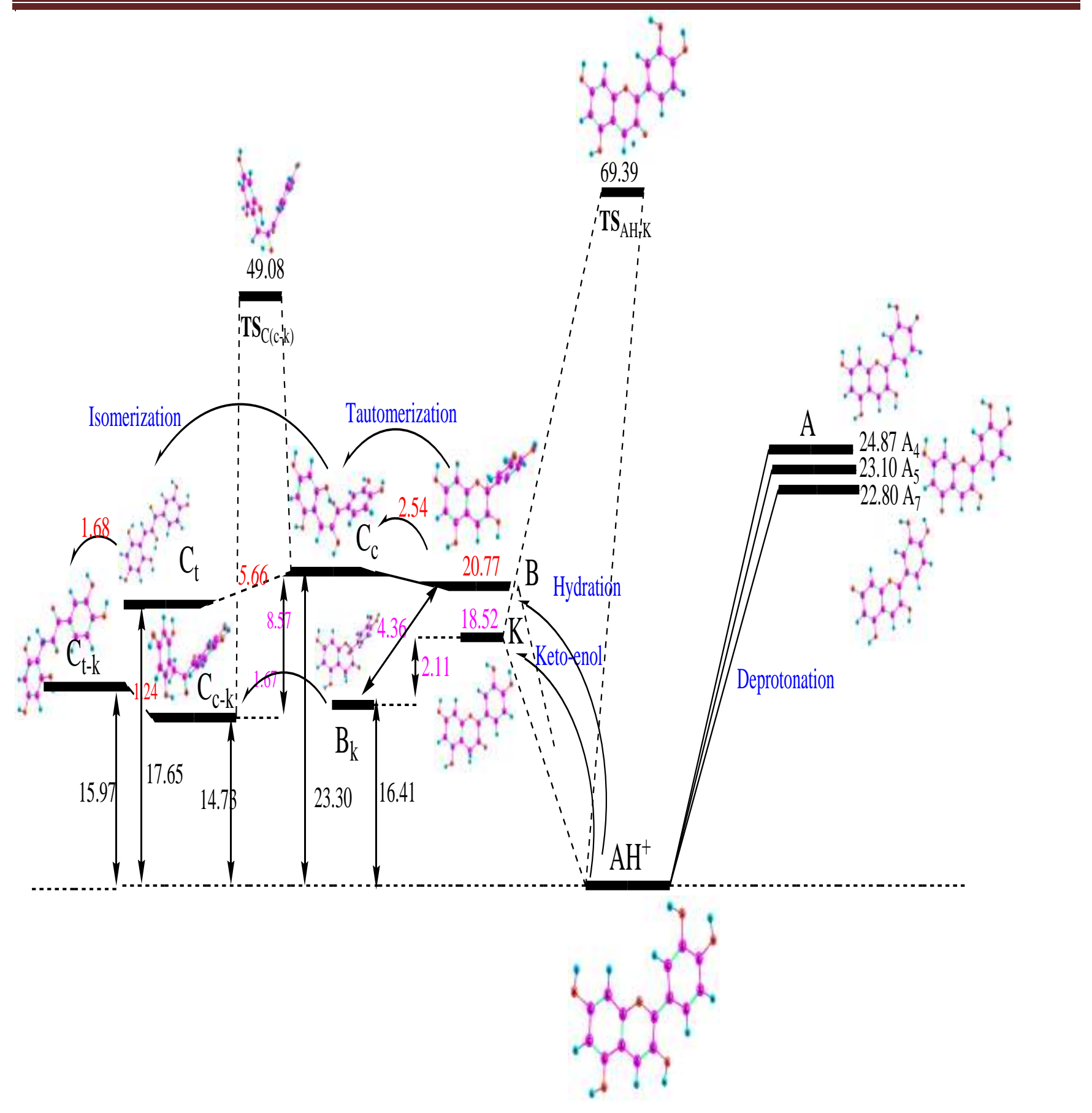

Figure 3. Potential energy diagram for the decomposition of cyanidin $\left(\Delta \mathrm{G}^{\mathrm{o}}, \mathrm{kcal} / \mathrm{mol}\right)$ at B3P86-D2/ccpVDZ in water. 


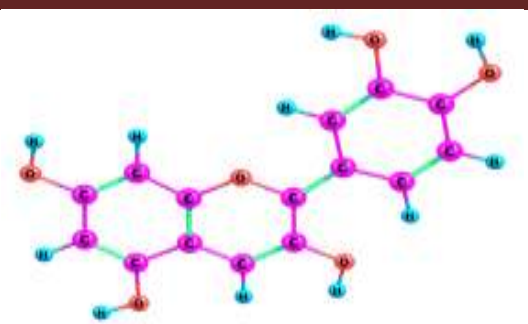

$\mathrm{Cy}\left(\mathrm{AH}^{+}\right)$

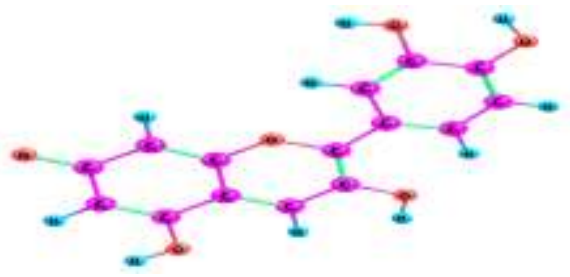

$\mathbf{A}_{7}$

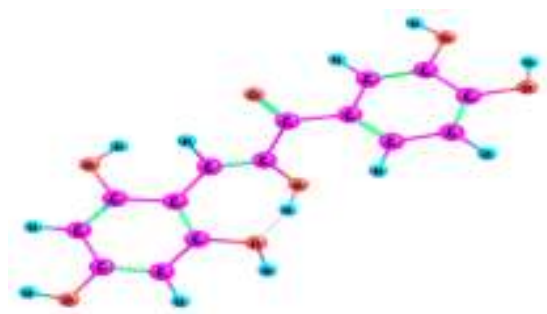

$\mathbf{C}_{\mathbf{t}}$

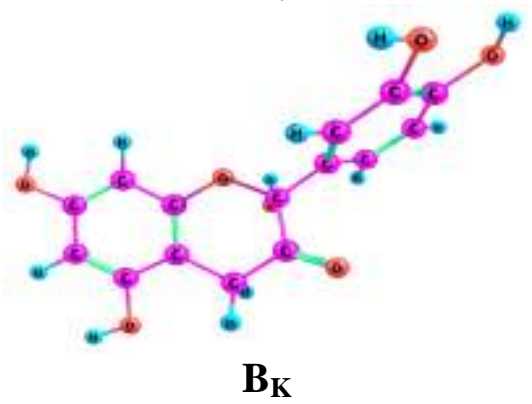

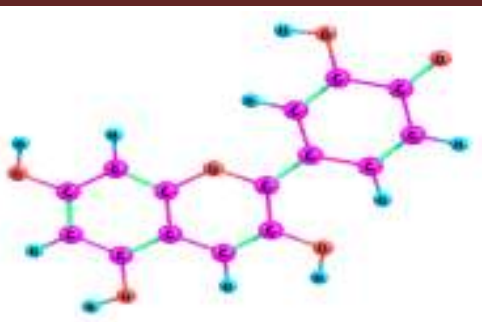

$\mathbf{A}_{4}$,

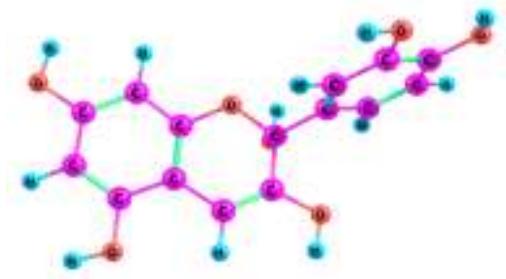

B

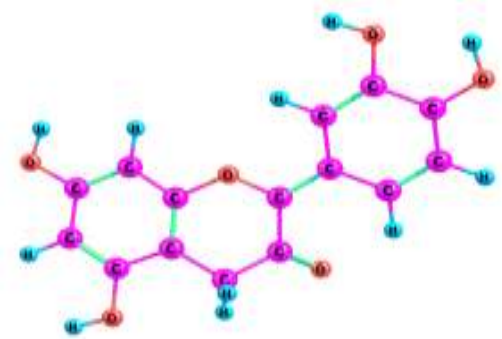

$\operatorname{Keto}(\mathbf{K})$

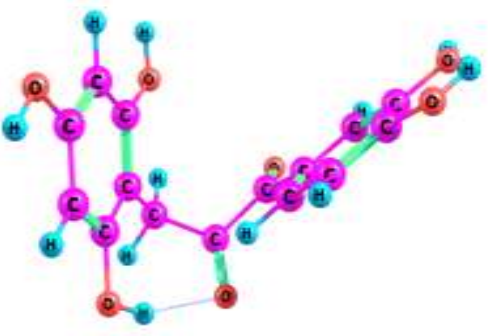

$\mathbf{D K}_{\mathbf{c}}$

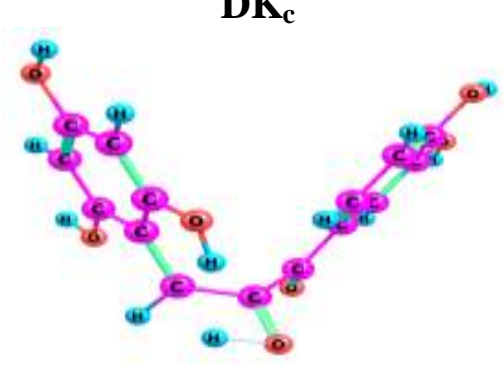

TS-C $\mathbf{c}-\mathbf{D K}_{\mathrm{c}}$

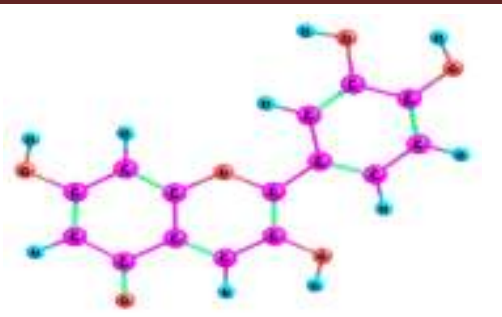

$\mathbf{A}_{5}$

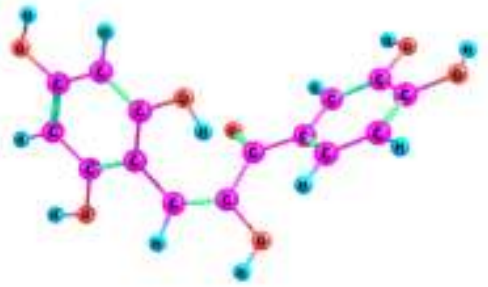

$\mathbf{C}_{\mathrm{c}}$

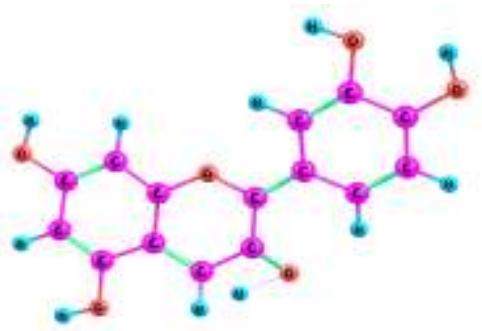

$\mathbf{T S}_{\mathrm{AH}+-\mathrm{K}}$

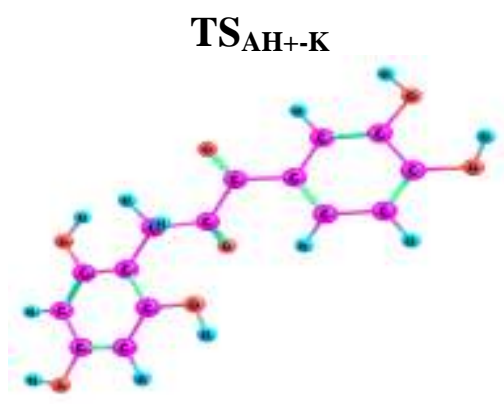

$\mathbf{D K}_{\mathbf{t}}$

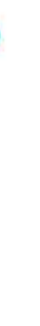

Figure 4: Optimized structures of cyanidin decomposition products at B3P86-D2/cc-pVDZ in water. 
Table 1: B3P86-D2/cc-pVDZ calculated equilibrium constants of cyanidin at $298 \mathrm{~K}$.

\begin{tabular}{ccccccccc}
$\boldsymbol{K}_{\mathrm{a} 4^{\prime}}$ & $\mathbf{p} \boldsymbol{K}_{\mathrm{a} 4^{\prime}}$ & $\boldsymbol{K}_{\mathrm{a} 5}$ & $\mathbf{p} \boldsymbol{K}_{\mathrm{a} 5}$ & $\boldsymbol{K}_{\mathrm{a} 7}$ & $\mathbf{p} \boldsymbol{K}_{\mathrm{a} 7}$ & $\boldsymbol{K}_{\mathrm{h}}$ & $\boldsymbol{K}_{\mathbf{t}}$ & $\boldsymbol{K}_{\mathbf{i}}$ \\
\hline $9.66 \mathrm{E}-12$ & 11.01 & $3.18 \mathrm{E}-10$ & 9.50 & $1.91 \mathrm{E}-10$ & $9.72(4.8)^{\mathrm{a}}$ & $5.88 \mathrm{E}-16$ & $\begin{array}{c}1.38 \mathrm{E}-02 \\
(0.56)^{\mathrm{a}}\end{array}$ & $1.41 \mathrm{E}+04$
\end{tabular}

${ }^{\mathrm{a}}$ ref. [44].

\section{Electronic properties}

The calculated longest wavelength of absorption $\left(\lambda_{\max }\right)$ of the studied equilibrium structures of cyanidin are presented in Table 2. As seen from Table 2, the maximum absorption bands for cyanidin flavylium cation, $487 \mathrm{~nm}$ in water is slightly underestimated relative to the experimental value of 515 $\mathrm{nm}$ [31]. For chalcone, the caculated $\lambda_{\max }$ is in agreement with previous experimental reports. The $\lambda_{\max }$ of chalcone was in the rangs of $(300-400,200-270 \mathrm{~nm})$ [45].

Table 2: calculated oscillator strength (f) and maximum wavelength $\left(\lambda_{\max }\right)$ for the cyanidin equilibrium structures at TD-B3P86-D2/cc-pVDZ in water.

\begin{tabular}{cccccc}
\hline Enol-structure & $\lambda_{\max }(\mathrm{nm})$ & $f$ & $\begin{array}{c}\text { Keto- } \\
\text { structure }\end{array}$ & $\lambda_{\max }(\mathrm{nm})$ & $f$ \\
\hline $\mathbf{A H}^{+}$ & 487 & 0.6139 & $\mathbf{A H}_{\mathbf{k}}^{+}$ & 364 & 0.3739 \\
$\mathbf{A}_{\mathbf{C}^{\prime}}$ & 485 & 0.9709 & & & \\
$\mathbf{A}_{\mathbf{C} 7}$ & 515 & 0.5353 & & & \\
$\mathbf{B}$ & 188 & 0.6171 & $\mathbf{B}_{\mathbf{k}}$ & 226 & 0.1245 \\
$\mathbf{C}$ & 201 & 0.2657 & $\mathbf{D K}_{\mathbf{c}}$ & 343 & 0.1342 \\
$\mathbf{C}_{\mathbf{t}}$ & 383 & 0.5181 & $\mathbf{D K}_{\mathbf{t}}$ & 337 & 0.1723 \\
\hline
\end{tabular}

\section{CONCLUSIONS}

In this study, thermochemistry and kinetics of cyanidin stability were calculated at B3P86D2/cc-pVDZ. The results obtained can be summarized as follows:

1 - Keto structures at 3-position is thermodynamically preferable reaction than hydration reaction.

2-Chalcone isomerization to 3-keto structure is thermodynamically and kinetically preferable than

flavylium cation isomerization to 3-keto form.

3-The hydroxyl group at position 3 of anthocynidin is responsible for cyaniding instability and plays an important role in decomposition of anthocyandin.

\section{REFERENCES}

I.Jackman, R. L.; Yada, R. Y.; Tung, M. A.; Speers, R. A. Anthocynins as Food Colorants-A Review. J. Food Biochem. 1987, 11 (3), 201-247.

II.He, J.; Giusti, M. M. Anthocyanins: Natural Colorants with Health-Promoting Properties. Annu. Rev. Food Sci. Technol. 2010, 1 (1), 163-187.

III.Aguilera, Y.; Mojica, L.; Rebollo-Hernanz, M.; Berhow, M.; De Mejía, E. G.; Martín-Cabrejas, M. A. Black Bean Coats: New Source of Anthocyanins Stabilized by $\beta$-Cyclodextrin Copigmentation in a Sport Beverage. Food Chem. 2016, 212, 561-570. 
IV.Dumbravă, A.; Georgescu, A.; Damache, G.; Badea, C.; Enache, I.; Oprea, C.; Gîrţu, M. A. Dye Sensitized Solar Cells Based on Nanocrystalline TiO2 and Natural Pigments. J. Optoelectron. Adv. Mater. 2008, 10 (11), 2996-3002.

V.Kimura, Y.; Maeda, T.; Iuchi, S.; Koga, N.; Murata, Y.; Wakamiya, A.; Yoshida, K. Characterization of Dye-Sensitized Solar Cells Using Five Pure Anthocyanidin 3-O-Glucosides Possessing Different Chromophores. J. Photochem. Photobiol. A Chem. 2017, 335, 230-238.

VI.Reque, P. M.; Steffens, R. S.; Jablonski, A.; FlÔres, S. H.; Rios, A. de O.; de Jong, E. V. Cold Storage of Blueberry (Vaccinium Spp.) Fruits and Juice: Anthocyanin Stability and Antioxidant Activity. J. Food Compos. Anal. 2014, 33 (1), 111-116.

VII.Yao, G.; Ma, X.; Cao, X.; Chen, J. Effects of Power Ultrasound on Stability of Cyanidin-3Glucoside Obtained from Blueberry. molecules 2016, 21, 1564.

VIII.Awika, J. M.; Rooney, L. W.; Waniska, R. D. Anthocyanins from Black Sorghum and Their Antioxidant Properties. Food Chem. 2005, 90, 293-301.

IX.Jordheim, M.; Aaby, K.; Fossen, T.; Skrede, G.; Andersen, Ø. M. Molar Absorptivities and Reducing Capacity of Pyranoanthocyanins and Other Anthocyanins. J. Agric. Food Chem. 2007, 55 (26), 10591-10598.

X.Awika, J. M.; Rooney, L. W. Sorghum Phytochemicals and Their Potential Impact on Human Health. Phytochemistry 2004, 65 (9), 1199-1221.

XI.Wallace, T. C.; Slavin, M.; Frankenfeld, C. L. Systematic Review of Anthocyanins and Markers of Cardiovascular Disease. Nutrients 2016, 8 (1), 1-13.

XII.Cassidy, A.; Mukamal, K. J.; Liu, L.; Franz, M.; Eliassen, A. H.; Rimm, E. B. High Anthocyanin Intake Is Associated with a Reduced Risk of Myocardial Infarction in Young and Middle-Aged Women. Circulation 2013, 127 (2), 188-196.

XIII.Turrini, E.; Ferruzzi, L.; Fimognari, C. Possible Effects of Dietary Anthocyanins on Diabetes and Insulin Resistance. Curr. Drug Targets 2017, 18 (6), 629-640.

XIV.Farrell, N.; Norris, G.; Lee, S. G.; Chun, O. K.; Blesso, C. N. Anthocyanin-Rich Black Elderberry Extract Improves Markers of HDL Function and Reduces Aortic Cholesterol in Hyperlipidemic Mice. Food Funct. 2015, 6 (4), 1278-1287.

XV.Golasz, L.; Silva, J.; Silva, S. Film with Anthocyanins as an Indicator of Chilled Pork Deterioration. Ciência e Tecnol. Aliment. 2013, 33, 155-162.

XVI.Harborne, J. B. Comperative Biochemistry of the Flavonoids; Aca- demic Press, London, New York, 1967. 
XVII.Welcha, C. R.; Wub, Q.; Simonb, J. E. Recent Advances in Anthocyanin Analysis and Characterization. Curr Anal Chem. 2008, 4 (2), 75-101.

XVIII.Dyrby, M.; Westergaard, N.; Stapelfeldt, H. Light and Heat Sensitivity of Red Cabbage Extract in Soft Drink Model Systems. Food Chem. 2001, 72 (4), 431-437.

XIX.Goto, T.; Kondo, T. Structure and Molecular Stacking of Anthocyanins- Flower Color Variation. Angew. Chem. Int. Ed 1991, 30, 17-33.

XX.Yoshida, K.; Mori, M.; Kondo, T. Blue Flower Color Development by Anthocyanins: From Chemical Structure to Cell Physiology. Nat. Prod. Rep. 2009, 26 (7), 884-915.

XXI.Castañeda-Ovando, A.; Pacheco-Hernández, M. de L.; Páez-Hernández, M. E.; Rodríguez, J. A.; Galán-Vidal, C. A. Chemical Studies of Anthocyanins: A Review. Food Chem. 2009, 113 (4), 859871.

XXII.Harborne, J. B. The Chromatographic Identification of Anthocyanin Pigments. J. Chromatogr. A $1958,1,473-488$.

XXIII.Brouillard, R.; Delaporte, B. Chemistry of Anthocyanin Pigments. 2.1 Kinetic and Thermodynamic Study of Proton Transfer, Hydration, and Tautomeric Reactions of Malvidin 3Glucoside. J. Am. Chem. Soc. 1977, 99 (26), 8461-8468.

XXIV.Mazza, G.; Brouillard, R. Color Stability and Structural Transformations of Cyanidin 3, 5Diglucoside and Four 3-Deoxyanthocyanins in Aqueous Solutions. J. Agric. Food Chem. 1987, 35, 422-426.

XXV.Trouillas, P.; Sancho-García, J. C.; De Freitas, V.; Gierschner, J.; Otyepka, M.; Dangles, O. Stabilizing and Modulating Color by Copigmentation: Insights from Theory and Experiment. Chemical Reviews. 2016, 4937-4982.

XXVI.Cavalcanti, R. N.; Santos, D. T.; Meireles, M. A. A. Non-Thermal Stabilization Mechanisms of Anthocyanins in Model and Food Systems-An Overview. Food Res. Int. 2011, 44 (2), 499-509.

XXVII.Torskangerpoll, K.; Andersen, Ø. M. Colour Stability of Anthocyanins in Aqueous Solutions at Various pH Values. Food Chem. 2005, 89 (3), 427-440.

XXVIII. Mazza, G.; Brouillard, R. Recent Developments in the Stabilization of Anthocyanins in Food Products. Food Chem. 1987, 25 (3), 207-225.

XXIX. Daravingas, G.; Cain, R. F. Thermal Degradation of Black Raspberry Anthocyanin Pigments in Model Systems. J. Food Sci. 1968, 33 (2), 138-142.

XXX. Nikkhah, E.; Khayamy, M.; Heidari, R.; Jamee, R. Effect of Sugar Treatment on Stability of Anthocyanin Pigments in Berries. J. Biol. Sci. 2007, 7 (8), 1412-1417. 
XXXI. El-Meligy, A. B.; Ishihara, T.; Oyama, K.; El-Nahas, A.; Yoshida, K. The First Synthesis of 3O-Methylcyanidin and the Effect of 3-O-Substitution on Stability Under Acidic Conditions. Heterocycles 2018, 79.

XXXII. Ratanapoompinyo, J.; Nguyen, L. T.; Devkota, L.; Shrestha, P. The Effects of Selected Metal Ions on the Stability of Red Cabbage Anthocyanins and Total Phenolic Compounds Subjected to Encapsulation Process. J. Food Process. Preserv. 2017, No. June 2016, 1-8.

XXXIII. Brauch, J. E.; Kroner, M.; Schweiggert, R. M.; Carle, R. Studies into the Stability of 3O-Glycosylated and 3,5-O-Diglycosylated Anthocyanins in Differently Purified Liquid and Dried Maqui (Aristotelia Chilensis (Mol.) Stuntz) Preparations during Storage and Thermal Treatment. J. Agric. Food Chem. 2015, 63 (39), 8705-8714.

XXXIV. Cabrita, L.; Fossen, T.; Andersen, Ø. M. Colour and Stability of the Six Common Anthocyanidin 3-Glucosides in Aqueous Solutions. Food Chem. 2000, 68 (1), 101-107.

XXXV. Mirsaeedghazi, H.; Emam-Djomeh, Z;; Ahmadkhaniha, R. Effect of Frozen Storage on the Anthocyanins and Phenolic Components of Pomegranate Juice. J. Food Sci. Technol. 2014, 51 (2), 382-386.

XXXVI. Hellström, J.; Mattila, P.; Karjalainen, R. Stability of Anthocyanins in Berry Juices Stored at Different Temperatures. J. Food Compos. Anal. 2013, 31 (1), 12-19.

XXXVII. Heredia, F. J.; Francia-Aricha, E. M.; Rivas-Gonzalo, J. C.; Vicario, I. M.; SantosBuelga, C. Chromatic Characterization of Anthocyanins from Red Grapes - I. pH Effect. Food Chem. 1998, 63 (4), 491-498.

XXXVIII. Di Meo, F.; Sancho Garcia, J. C.; Dangles, O.; Trouillas, P. Highlights on Anthocyanin Pigmentation and Copigmentation: A Matter of Flavonoid $\pi$-Stacking Complexation to Be Described by DFT-D. J. Chem. Theory Comput. 2012, 8 (6), 2034-2043.

XXXIX. Vallverdú-queralt, A.; Biler, M.; Meudec, E.; Guernevé, C. Le; Vernhet, A.; Mazauric, J.; Legras, J.; Loonis, M.; Trouillas, P.; Cheynier, V.; et al. P -Hydroxyphenyl-Pyranoanthocyanins : An Experimental and Theoretical Investigation of Their Acid - Base Properties and Molecular Interactions. Int. J. Mol. Sci. 2016, 17 (11), 1842.

XL. Rustioni, L.; Di Meo, F.; Guillaume, M.; Failla, O.; Trouillas, P. Tuning Color Variation in Grape Anthocyanins at the Molecular Scale. Food Chem. 2013, 141 (4), 4349-4357.

XLI. Trouillas, P.; Marsal, P.; Siri, D.; Lazzaroni, R.; Duroux, J. L. A DFT Study of the Reactivity of $\mathrm{OH}$ Groups in Quercetin and Taxifolin Antioxidants: The Specificity of the 3-OH Site. Food Chem. 2006, 97 (4), 679-688.

XLII. Marenich, A. V; Cramer, C. J.; Truhlar, D. G. Universal Solvation Model Based on Solute Electron Density and on a Continuum Model of the Solvent Defined by the Bulk Dielectric Constant and Atomic Surface Tensions. J. Phys. Chem. B 2009, 113 (18), 6378-6396. 
XLIII. Frisch, M. J.; Trucks, G. W.; Schlegel, H. B.; Scuseria, G. E.; Robb, M. A.; Cheeseman, J. R.; Scalmani, G.; Barone, V.; Mennucci, B.; Petersson, G. A.; et al. Gaussian 09 Revision A.1, Gaussian Inc. Wallingford CT. 2009.

XLIV. Cabrita, L.; Petrov, V.; Fernando, P. On the Thermal Degradation of Anthocyanidins: Cyanidin. RSC Adv. 2014, 4 (36), 18939-18944.

XLV. Levi, M. A. B.; Scarminio, I. S.; Poppi, R. J.; Trevisan, M. G. Three-Way Chemometric Method Study and UV-Vis Absorbance for the Study of Simultaneous Degradation of Anthocyanins in Flowers of the Hibiscus Rosa-Sinensys Species. Talanta 2004, 62 (2), 299-305. 